\title{
Biosorption Performance of Biodegradable Polymer Powders for the Removal of Gallium(III) ions from Aqueous Solution
}

\author{
Ching-Hwa Lee ${ }^{1,}$, Hang-Yi Lin', Elon I. Cadogan', Srinivasa R. Popuri' ${ }^{2}$, Chia-Yuan Chang ${ }^{3}$ \\ ${ }^{1}$ Da-Yeh University, Department of Environmental Engineering, Changhua 51591, Taiwan (ROC) \\ ${ }^{2}$ The University of the West Indies Cave Hill Campus, Department of Biological and Chemical Sciences, 11000 Barbados \\ ${ }^{3}$ Chia Nan University of Pharmacy and Science, Department of Environmental Engineering and Science, Tainan 71710, \\ Taiwan \\ "Corresponding author: chl@mail.dyu.edu.tw
}

\begin{abstract}
Gallium $(\mathrm{Ga})$ is considered an important element in the semiconducting industry and as the lifespan of electronic products decrease annually Ga-containing effluent has been increasing. The present study investigated the use of biodegradable polymer powders, crab shell and chitosan, in the removal of $\mathrm{Ga}(\mathrm{III})$ ions from aqueous solution. $\mathrm{Ga}$ (III) biosorption was modeled to Lagergren-first, pseudo-second order and the Weber-Morris models. Equilibrium data was modeled to the Langmuir, Freundlich and Langmuir-Freundlich adsorption isotherms to determine the probable biosorption behavior of $\mathrm{Ga}(\mathrm{III})$ with the biosorbents. The biosorbents were investigated by Fourier Transform Infrared Spectroscopy, X-ray Diffraction and Scanning Electron Microscopy/ Energy Dispersive Spectra analysis.
\end{abstract}

Keywords: chitosan, crab shell powder, gallium, Langmuir-Freundlich, kinetics.

\section{INTRODUCTION}

Gallium $(\mathrm{Ga})$ is an important doping element in the semiconductor industry since the discovery of its semiconducting properties in the 1970's and its use is increasing in the electronic industry worldwide ${ }^{1-4}$. However, the sources of $\mathrm{Ga}$ are limited, thus technologies for Ga recovery remain important to reduce costs of Ga containing electronics. The dawn of the technological era has increased the demand for high performance electronics with outstanding displays, thus increasing the market value of $\mathrm{Ga}$ and related semiconductors ${ }^{5,6}$. Over the period of 1992 to 2002 the importation of Ga for electronics increased from $17 \%$ to $65 \%$ in the United States of America (USA) ${ }^{1}$. In 2002 the importation of Ga into the USA was valued at US $\$ 6$ million $^{7}$. After the rapid growth period, 2002 to 2012, in the electronic industry, the imports of Ga to the USA for electronic components accounted for $99 \%$ of total Ga consumption and were valued at about US \$16 million for the year $2013^{8}$.

Due to the high market value of $\mathrm{Ga}$ and its limited resources, various technologies have been applied over the past few years for the recovery of Ga. However, there is still a need for the implementation of technologies for the removal of $\mathrm{Ga}$ from aqueous streams to reduce the heavy metal content from industrial effluents. The recovery of Ga from aqueous solutions can be achieved through several processes including: chemical precipitation, solvent extraction, ion exchange etc. ${ }^{9-12}$. These methods are often ineffective and/or expensive when used for the removal of metal ions at very low concentrations. Biosorption continues to receive attention for the treatment of metal containing waste waters due to advantages of easy regeneration and minimal solid-liquid separation operation ${ }^{13}$.

Crustacean shell powders such as crabs, shrimps and lobsters have the potential to remove metal ions from aqueous solutions due to the properties of structural stability, porosity, large surface areas, hydrophilicity, and metal binding functional groups ${ }^{14}$. Crab shell waste represents a promising adsorbent due to its low costs and little treatment needed for the preparation of the biosorbent. Crayfish carapace shell powder was used as a low cost adsorbent for the successful removal of divalent metal ions such as copper, cadmium, zinc, and lead ${ }^{15}$. Rannia rannia crab shell contains large amounts of mineral salts, proteins and chitin, which has calcium carbonate, sulfur and acetyl amine functional groups that chelates with metal ions through donor ligands ${ }^{16}$.

Chitosan, ((1-4)-linked2acetamido-2-deoxy- $\beta$-D-glucan), is an isolated product of second most abundant natural polymer, chitin. The biopolymer chitosan can be viewed as an economical and attractive material due to various possible chemical modifications, which can be made to improve its biocompatibility and biodegradability ${ }^{17-19}$. Previous studies reported the various modifications of chitosan to increase its adsorption capacity for metal ions ${ }^{20}$. These chemical modifications can improve the biocompatibility, chemical stability, mechanical strength and other physicochemical properties but are limited in practical application due to the high costs required for the chemical treatment ${ }^{15}$. Therefore, this study utilizes the chitosan powder extracted from Rannia rannia crab and its plain shell powder as biosorbents for the removal of $\mathrm{Ga}$ (III) ion. Though crustacean shell powders were used as low costs biosorbents for the removal of heavy metals and non-metals, to the best of our knowledge this is the first kind of study that uses crab shell powder and chitosan powder extracted from Rannia rannia crab for the removal of the heavy metal ion Ga(III).

The main objective of this study is to evaluate the biosorption behavior and capacities of crab shell powder and chitosan powder for the biosorption of $\mathrm{Ga}$ (III). The subsequent adsorption data is subjected to kinetic models to determine the probable kinetic order of biosorption and applied to isotherm models for the determination of the possible mechanism of biosorption. The biosorbents are characterized to confirm the accumulation of gallium on the surface of the biosorbents. 


\section{MATERIAL AND METHODS}

\section{Material}

Stock solutions of various concentrations of $\mathrm{Ga}(\mathrm{III})$ were prepared by diluting the original solution of 1000 $\mathrm{mgL}^{-1}$ obtained from Merck Co. Ltd. Germany. The $\mathrm{Ga}(\mathrm{III})$ was present in the form of $\mathrm{Ga}_{2} \mathrm{O}_{3}$ in $2-3 \% \mathrm{HNO}_{3}$ solution. Each stock solution was used within 24 hours of dilution to reduce the possible micro-precipitation of the metal ion. Analytical grade hydrochloric acid, nitric acid and sodium hydroxide were obtained from Katayama Chemical Co. Ltd. Taiwan. Deionized water was used throughout this study for metal ion dilutions.

\section{Preparation of biosorbents}

Waste crab shells, were collected from a local restaurant in Taiwan. These shells were washed with deionized water and sun dried for 24 hours. The dried shells were crushed to particle size of 50-mesh. For biosorption experiments, 50-mesh crab shells were used directly. Chitosan was extracted from crab shells through several chemical methods such as: deproteinization, demineralization, deacetylation, and decoloration. The detailed experimental procedure was described elsewhere ${ }^{21}$. The obtained chitosan powder was used as another biosorbent.

\section{Biosorption Studies}

Biosorption experiments were carried out in batch mode by studying the effect of agitation time, $\mathrm{pH}$ and initial metal ion concentration. For each test $25 \mathrm{~mL}$ of the required $\mathrm{Ga}(\mathrm{III})$ ion concentration (10-100 $\mathrm{mg} / \mathrm{L}$ ) was added to a known mass of biosorbent powder in 50 $\mathrm{mL}$ Erlenmeyer flask and agitated with a speed of 60 $\mathrm{rpm}$ at $25^{\circ} \mathrm{C}$ in a temperature controlled rotary shaker. The $\mathrm{pH}$ of the solution was adjusted accordingly with $0.1 \mathrm{~N} \mathrm{HCl}$ or $0.1 \mathrm{~N} \mathrm{NaOH}$. During these studies as one parameter was varied all other parameters were kept constant to evaluate the effect of the varied parameter on adsorption capacity. The adsorbent was separated by filtration using a polyvinylidene fluoride syringe filter after the adsorption capacity reached equilibrium and the aqueous-phase concentration of $\mathrm{Ga}(\mathrm{III})$ was determined by Inductively coupled Plasma-Atomic Emission spectrophotometer (ICP-AES). The equilibrium uptake capacity of the biosorbent powders for $\mathrm{Ga}(\mathrm{III})$ ion was calculated according to mass balance equation,

$\mathrm{q}_{\mathrm{t}}=\left(\mathrm{C}_{0}-\mathrm{C}_{\mathrm{t}}\right) \frac{\mathrm{v}}{\mathrm{m}}$

where $q_{t}$ was the amount adsorbed per unit mass of adsorbent $\left(\mathrm{mg} \mathrm{g}^{-1}\right), C_{0}$ and $C_{t}$ were, respectively, initial and equilibrium concentrations of metal ion $\left(\mathrm{m} \mathrm{gL}^{-1}\right)$, $m$ was the mass of adsorbent $(\mathrm{g})$ and $v$ was volume of solution in liters. The experiments were controlled by conducting the studies with metal ion solutions in absence of biosorbent and found no metal adsorption by the walls of the container occurred. Standard deviation and analytical errors were calculated by repeating the experiments three times and maximum error was found to be within $\pm 5 \%$.

\section{Characterization of biosorbents}

\section{Fourier Transform Infrared (FTIR) Studies}

FTIR spectra of crab shell and chitosan powders were recorded using a Perkin-Elmer 1600 spectrometer. The samples were formed into pellets with $\mathrm{KBr}$. Analysis was conducted within the range of wavelength $4000-500 \mathrm{~cm}^{-1}$ at $4 \mathrm{~cm}^{-1}$ resolutions and 20 scan.

\section{XRD analysis}

An X-ray diffractometer (Shimadzu XRD-6000) was used to analyze the solid-state morphology of the biosorbents. X-rays of wavelength $1.5406 \AA$ were generated by a $\mathrm{Cu} \mathrm{K \alpha}$ source. The angle of diffraction was varied from 5 to 35 degrees.

\section{FE-SEM-EDS studies}

The surface morphology of the biosorbent powders was recorded using a multi-function field emission scanning electron microscope (FE-SEM, Joel JSM-7401F) at x1000 magnification. The energy dispersion spectrum (EDS) was generated with a voltage acceleration of $15 \mathrm{kV}$ simultaneously as the electron image was captured using an equipped PentaFETx3-7585 EDS. The dried samples $\left(105^{\circ} \mathrm{C}\right)$ were deposited on a brass holder under vacuum pressure.

\section{RESULTS AND DISCUSSION}

\section{Biosorbent Characterization}

\section{FTIR studies}

FTIR studies were conducted to identify the possible functional groups present in the biosorbent powders and the corresponding spectra were presented in Figure 1. From spectra it was observed that there were prominent peaks for key functional groups in both the crab shell and chitosan powders. The absorption peak at $\sim 3630$ $\mathrm{cm}^{-1}$ was analogous to the $-\mathrm{OH}$ stretching mode in the crab shell powder. The broad absorption band observed at $3294 \mathrm{~cm}^{-1}$ was assigned to the $-\mathrm{OH}$ and $-\mathrm{NH}$ stretching for chitosan powder and other prominent peaks observed at $1420 \mathrm{~cm}^{-1}$ and $1047 \mathrm{~cm}^{-1}$ were attributed to

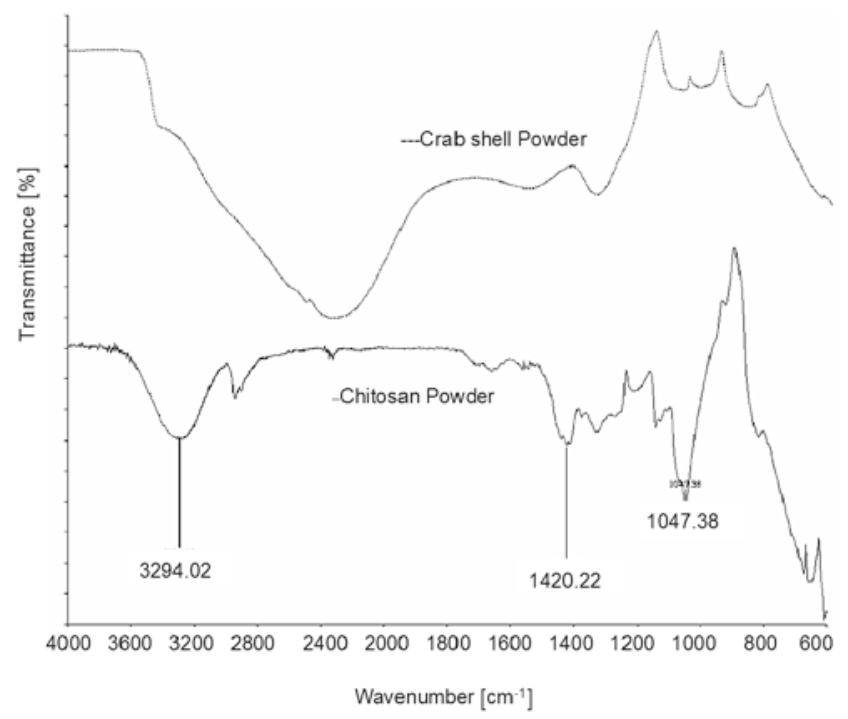

Figure 1. FTIR spectra of Crab shell powder (a), chitosan powder 
the amide and C-O-C linkages respectively ${ }^{22}$. Based on the literature and the chemistry between chitosan and metal ions these functional groups were identified as the main functional groups responsible for metal uptake ${ }^{26}$.

\section{XRD studies}

Crystal diffraction studies were conducted for both the biosorbents before and after $\mathrm{Ga}$ (III) adsorption and these diffractograms were shown in Figure 2. The changes in the crystal behavior of the biosorbents with metal loading were generally evaluated by the changes in the crystal fraction ${ }^{23}$. The crystal percentages crab shell and chitosan powders were $31.98 \%$ and $38.17 \%$ respectively. After adsorption, the intensity of the peaks increased which corresponded to the increase in crystal strength of the biosorbents and was speculated to be due to $\mathrm{Ga}(\mathrm{III})$ uptake. The crystallinity percentages for the biosorbents after $\mathrm{Ga}(\mathrm{III})$ uptake were $41.40 \%$ and $45.01 \%$ for crab shell and chitosan powders respectively. Low crystallinity in the original crystal structure of the biosorbent aided in the uptake of metal ions as high crystallinity hinders metal uptake capacity of adsorbents. Generally, at lower crystallinity, a greater increase in crystal percentage was seen after $\mathrm{Ga}(\mathrm{III})$ uptake, these changes were $9.42 \%$ and $6.93 \%$ respectively for crab shell and chitosan powders.

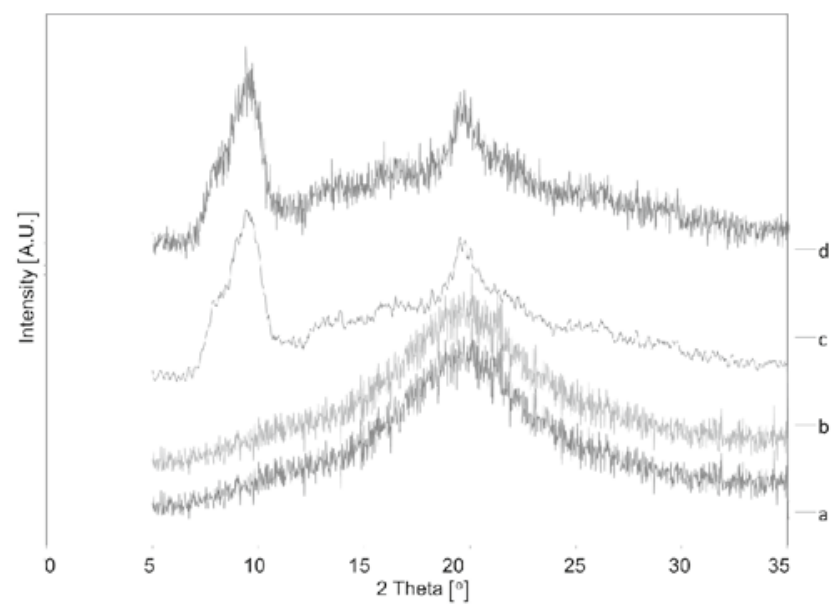

Figure 2. X-Ray diffractogram crab shell powder (a), chitosan powder (b), crab shell powder after Ga adsorption (c) and chitosan powder after Ga adsorption (d)

\section{SEM/EDS studies}

The size and shape of the adsorbent has an impact on the adsorption capacity of the adsorbent. Thus, the surface morphologies of the biosorbents were investigated via SEM/EDS. These SEM/EDS images were shown in Figure 3. The surface of the crab shell powder appeared to be compact and may be due to the packing of the powder onto the brass holder of the SEM platform. In this image small fractures on the surface were observed which indicates the rough surface structure. Subsequent to $\mathrm{Ga}(\mathrm{III})$ adsorption the crab shell powder appeared as small granules of size ranging from about $1 \mu \mathrm{m}$ to $20 \mu \mathrm{m}$ with $\mathrm{Ga}$ on the surface. In addition, the trace magnesium and phosphorus observed before $\mathrm{Ga}$ (III) adsorption may have dissolved in solution and thus were not seen in the EDS after adsorption. The morphology of the chitosan powder was non-uniform with fractures and ridges on the compacted powder. In addition, after biosorption, Ga appeared on the surface of the powder and the surface appeared to be more uniform in morphology as less fractures and ridges were observed. This could be due to the accumulation of $\mathrm{Ga}$ (III) ion into the factures on the chitosan surface.

\section{Biosorption Studies}

\section{Adsorption kinetics and effect of time on Gallium bio- sorption}

The effect of agitation time on the adsorption of $\mathrm{Ga}(\mathrm{III})$ from aqueous solution was investigated at a concentration of $10 \mathrm{mg} / \mathrm{L}$. The initial $\mathrm{pH}$ of the solution was $\sim 2.4$ and the $\mathrm{Ga}(\mathrm{III})$ ions present were produced by the dissociation of $\mathrm{Ga}_{2} \mathrm{O}_{3}$ in $2-3 \% \mathrm{HNO}_{3}$ solution. $100 \mathrm{mg}$ of the biosorbent was added to $25 \mathrm{~mL}$ of the $\mathrm{Ga}$ (III) solution in a $50 \mathrm{~mL}$ sample vial and agitated at $60 \mathrm{rpm}$ in a rotary shaker with the temperature maintained at $25 \pm 0.5^{\circ} \mathrm{C}$. The biosorption capacity was recorded at different time intervals and also the percentage of $\mathrm{Ga}(\mathrm{III})$ adsorption was calculated (Fig. 4) from the equation below:

$\% \mathrm{Ga}(\mathrm{III})$ biosorption $=\frac{\left(\mathrm{C}_{0}-\mathrm{C}_{\mathrm{t}}\right)}{\mathrm{C}_{0}} \times 100$

The percent of Ga(III) adsorption with crab shell and chitosan powder was achieved more than $50 \%$ within a minute and the adsorption continued up to 30 minutes, as was shown in Figure 4. The adsorption process reached to equilibrium in 30 minutes with chitosan powder, but reached to equilibrium after 90 minutes with crab shell powder. However, the Ga(III) uptake by the crab shell powder was about $20 \%$ less than that of chitosan initially and the difference reduces as time progressed. At 120 minutes the percentage removal of $\mathrm{Ga}(\mathrm{III})$ from aqueous solution was about $88 \%$ and $97 \%$ for crab shell and chitosan powder respectively.

To understand the kinetic mechanisms involved for the biosorption of $\mathrm{Ga}(\mathrm{III})$ onto these biosorbents, the Lagergren pseudo-first order, pseudo-second order and Weber-Morris intra-particle diffusion models were used to model the kinetic data. The Lagergren pseudo-first order mechanism describes the kinetic process of liquid-solid phase adsorptions and the adsorption rate was based on the adsorption capacities of the biosorbents. The linearized form of the pseudo first order equation was shown below:

$\log \left(q_{e}-q_{t}\right)=\log q_{e}-\left(\frac{k_{1}}{2.303}\right) t$

where $q_{e}$ is the equilibrium uptake of $\mathrm{Ga}(\mathrm{III})(\mathrm{mg} / \mathrm{g}), q_{t}$ is the amount of $\mathrm{Ga}(\mathrm{III})$ adsorbed at time $t(\mathrm{mg} / \mathrm{g}), k_{1}$ is the Legergren rate constant. The pseudo-second order assumes that the rate limiting step in adsorption process could be dominated by chemical adsorption ${ }^{24,25}$. Thus, the linearized form of the pseudo first order equation was shown below:

$\frac{t}{q_{t}}=\frac{1}{k_{2} q_{e}^{2}}+\frac{t}{q_{e}}$

Where $k_{2}$ is the pseudo-second order rate constant. For the determination of which order the adsorption of $\mathrm{Ga}(\mathrm{III})$ follows for the biosorbents crab shell and chitosan powder, a comparison of the theoretical values 

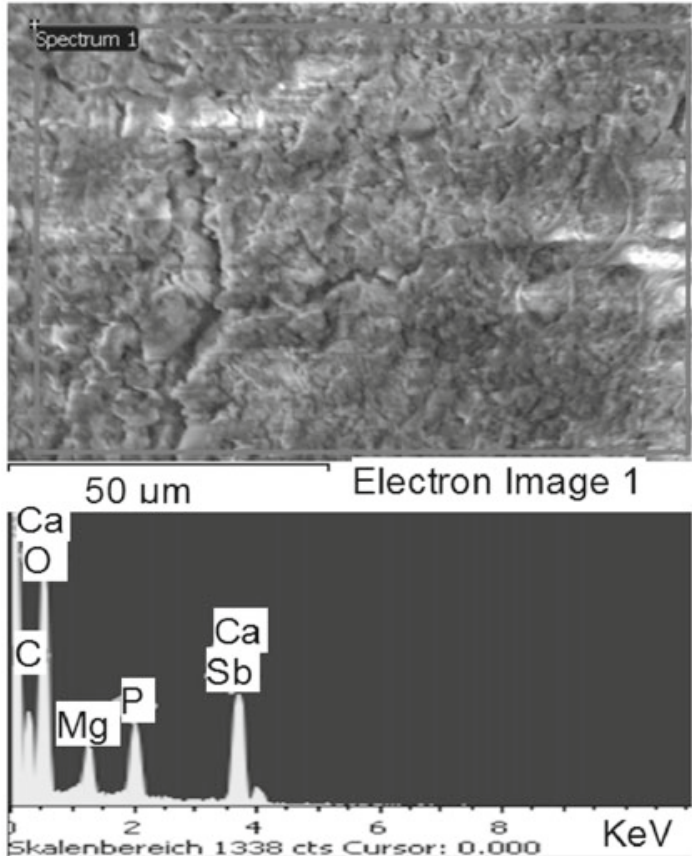

(a)
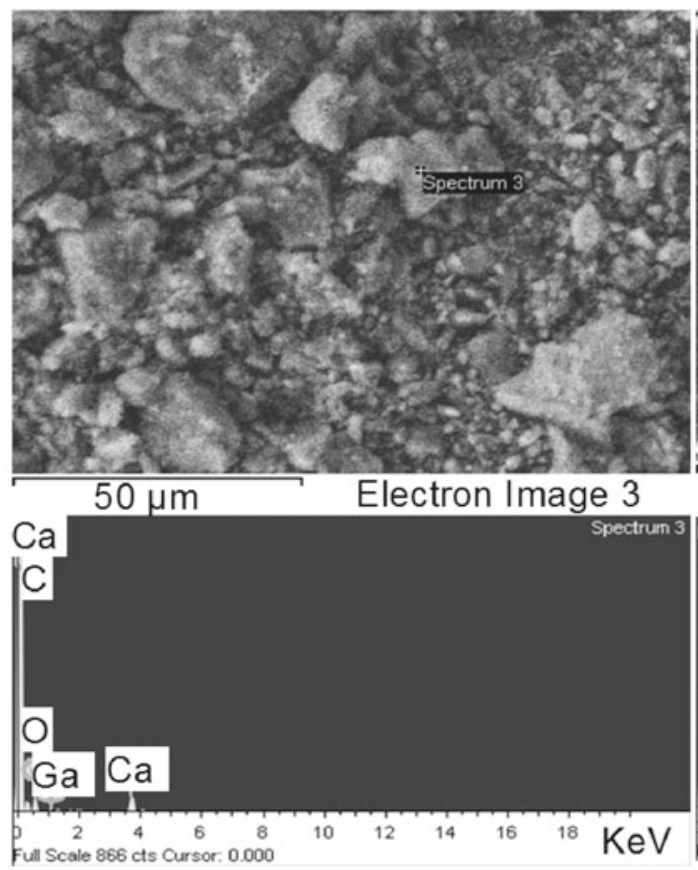

(c)

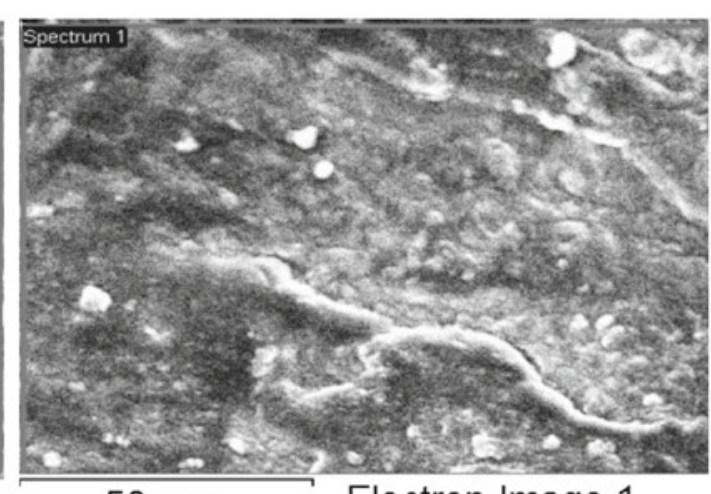

$50 \mu \mathrm{m} \quad$ Electron Image 1

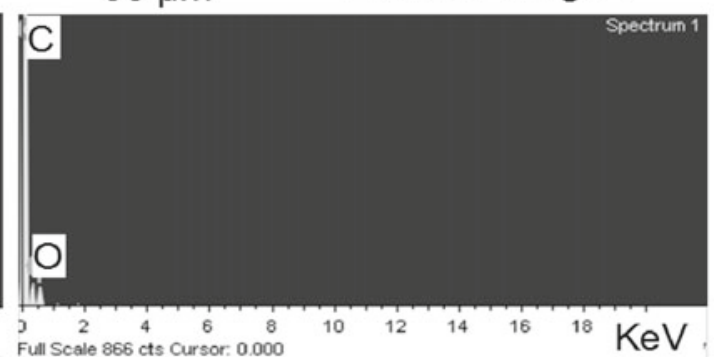

(b)

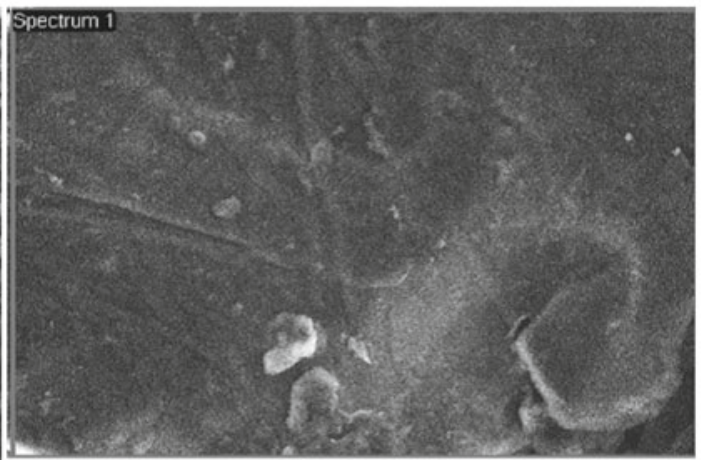

$50 \mu \mathrm{m} \quad$ Electron Image 1

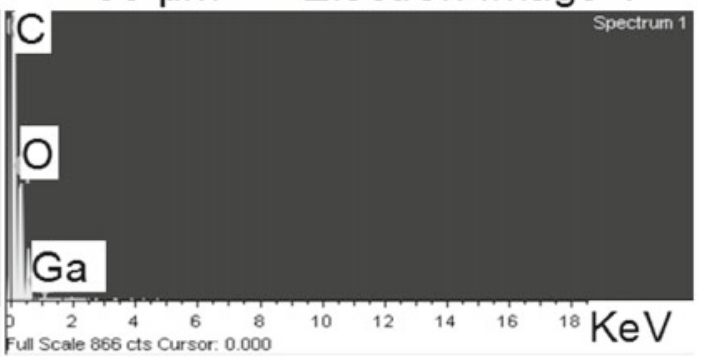

(d)

Figure 3. SEM/EDS spectra of biosorbents before and after Ga adsorption. Crab shell powder (a), chitosan powder (b), crab shell powder after Ga adsorption (c) and chitosan powder after Ga adsorption (d)

obtained from the kinetic plots were examined and the results were presented in Table 1 and Figure 5. Based on the correlation coefficients of the linear models it was observed that both biosorbents were closely followed the pseudo-second order kinetic model. In addition, the calculated equilibrium adsorption $\left(\mathrm{q}_{\mathrm{e}, \mathrm{cal}}\right)$ was similar to that of the experimental data. However, although the pseudo-second order model had a higher correlation coefficient, the correlation coefficient of the Lagergren-pseudo first order model could possibly describe the adsorption kinetics during the initial stage of biosorption. The Langergren kinetic model postulates that this initial adsorption was influenced by the reversible equilibrium between liquid and solid phases ${ }^{26}$.
To further understand the sorption kinetics of this biosportion process, the Weber-Morris intra-particle diffusion model was used to interrogate the kinetic data. The Weber-Morris model is based on the assumption that the solute uptake $\left(\mathrm{q}_{\mathrm{t}}\right)$ varies proportionally with time $\left(t^{0.5}\right)$, according to the equation below:

$q_{t}=k_{m} t^{0.5}$

where $k_{m}$ is the intra-particle diffusion rate constant. The plot $q_{t}$ Vs. $t^{0.5}$ was generally passed through the origin if the adsorption process is only limited by intra-particle diffusion. Further, to determine whether the biosorption process of $\mathrm{Ga}(\mathrm{III})$ onto the crab shell and chitosan powder was controlled only by particle-diffusion, the kinetic 


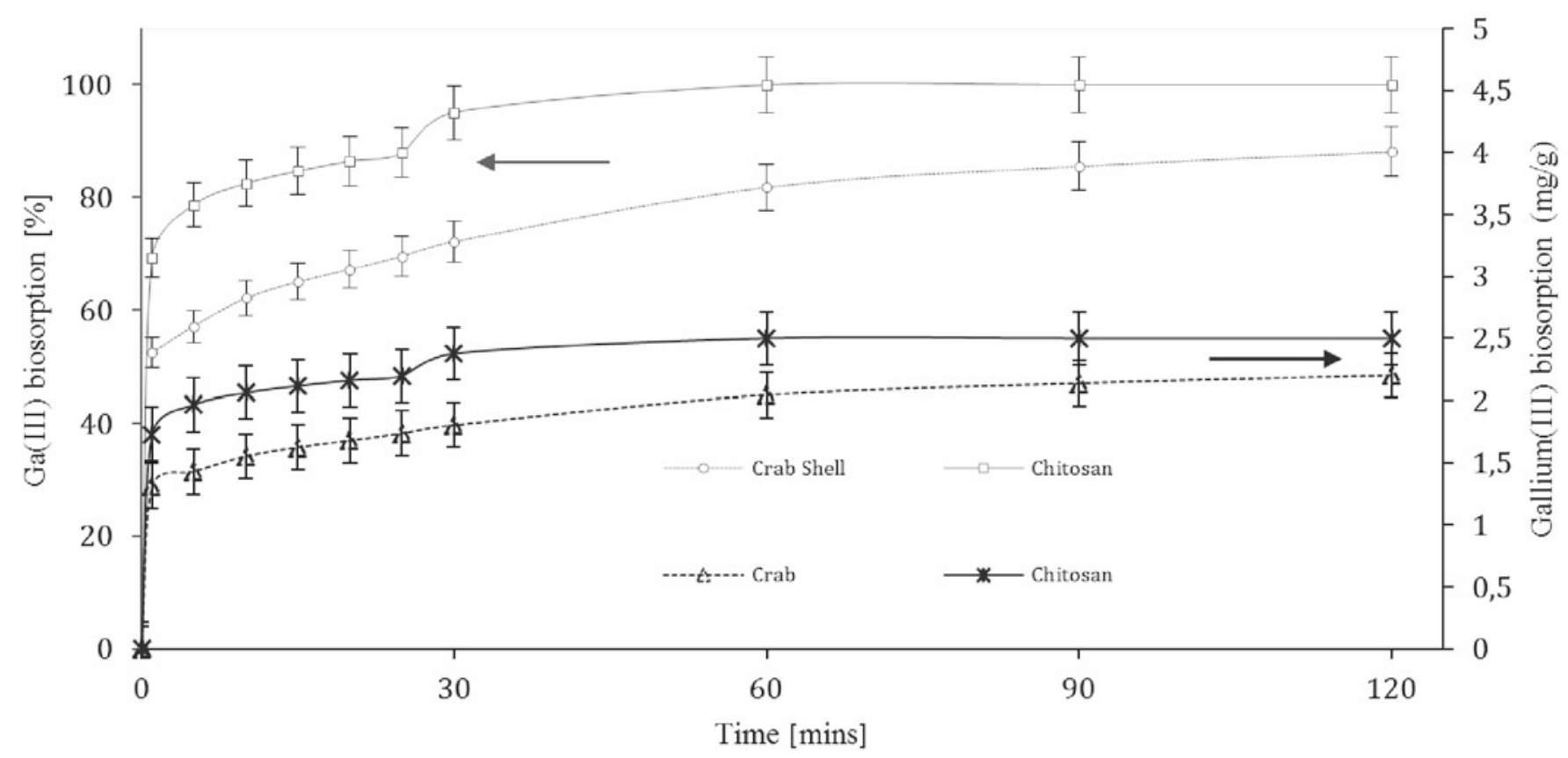

Figure 4. Effect of agitation time on biosorption of $\mathrm{Ga}(\mathrm{III})$ onto crab shell and chitosan powder. Conditions: $\mathrm{Ga}(\mathrm{III})$ ion concentration $10 \mathrm{mg} / \mathrm{L}, 100 \mathrm{mg}$ biosorbent, $\mathrm{pH} 2.4$ with an agitation speed of $60 \mathrm{rpm}$ at $25^{\circ} \mathrm{C}$

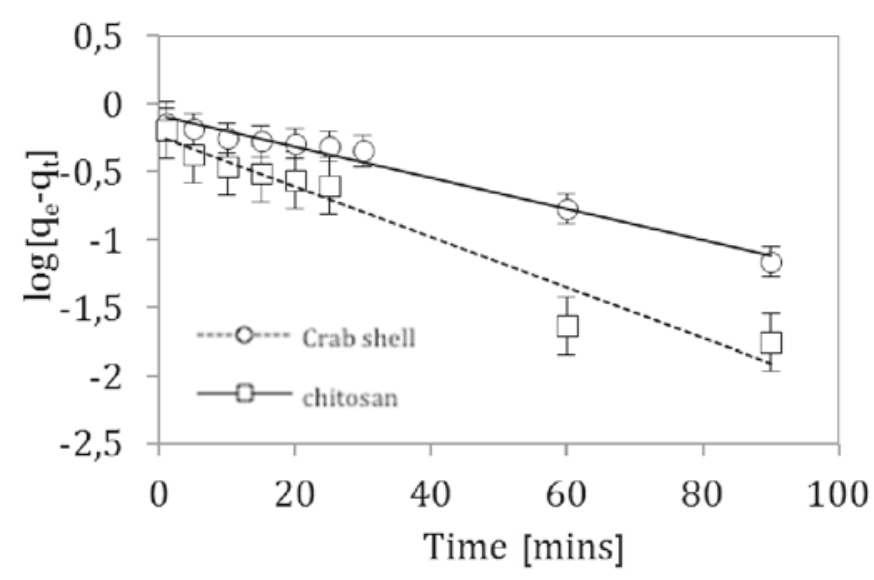

(a)

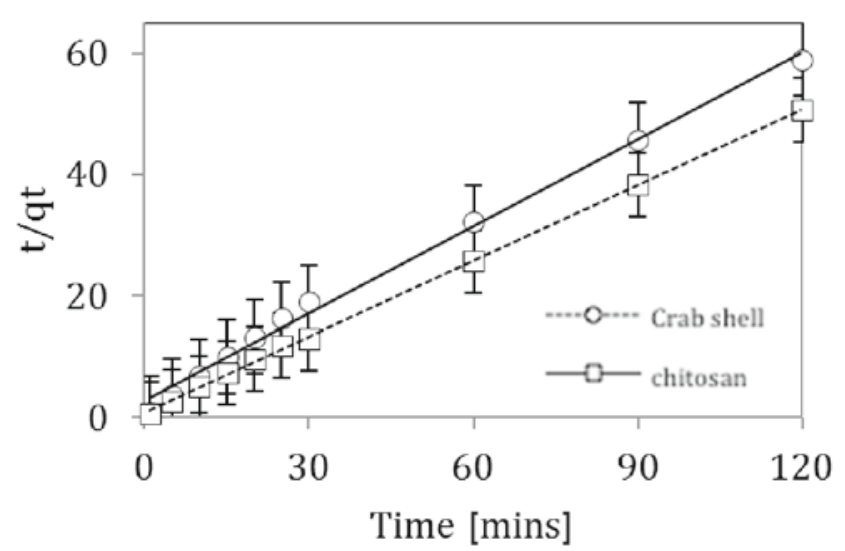

(b)

Figure 5. (a) Lagergren pseudo-first order sorption kinetics of Ga(III) and (b) Pseudo-second order sorption kinetics of $\mathrm{Ga}(\mathrm{III})$ onto crab shell and chitosan powder. Conditions: $\mathrm{Ga}(\mathrm{III})$ ion concentration $10 \mathrm{mg} / \mathrm{L}, 100 \mathrm{mg}$ biosorbent, $\mathrm{pH} 2.4$ with an agitation speed of $60 \mathrm{rpm}$ at $25^{\circ} \mathrm{C}$

data was applied to the particle diffusion controlled process model represented as follows:

$\ln (1-\alpha)=-k_{p} t$

$\alpha=[M]_{t}^{n+} /[M]_{e}^{n+}$

where $k_{p}$ is the particle diffusion coefficient corresponding to the particle size and $[M]_{t}$ is the $\mathrm{Ga}(\mathrm{III})$ concentration at a given time and $[M]_{e}$ is the $\mathrm{Ga}$ (III) concentration at equilibrium. In this kinetic model the linear plot of $\ln (1-\alpha)$ Vs. $t$, is a measure of whether the Ga(III) adsorption is intra-particulate diffusion controlled and the diffusivity onto the surface of the biosorbents was independent of the degree of adsorption.

The Weber-Morris plot, as shown in Figure 6a, was divided into three different regions and resulted in three different correlation coefficients. The rate constants of these regions were presented in Table 2. The first region in this plot corresponds to the initial fast mass transfer to the external surface of the biosorbents. The second stage relates the gradual uptake that reflects the intra-particle diffusion as the rate limiting step inside the biosorbents. The third stage relates to equilibrium uptake of the $\mathrm{Ga}(\mathrm{III})$ ion by the biosorbents. From Figure $6 \mathrm{~b}$ the linear plots of $\ln (1-\alpha)$ Vs. $t$ corresponds to the intra-particulate diffusivity and the particle diffusion ${ }^{27}$ coefficient $\left(k_{p}\right)$ values were presented in Table 2 . In general, if the $k_{p}$ values are higher than the Weber-Morris rate constants, $k_{1}, k_{2}$ or $k_{3}$, the adsorption process is not controlled by only the intra-particle diffusion ${ }^{28}$.

Table 1. Lagergren first and second order rate constants for adsorption of $\mathrm{Ga}(\mathrm{II})$ on crab shell powder and chitosan

\begin{tabular}{|l|c|c|c|c|c|}
\hline Biosorbent & $\mathrm{k}_{1}\left[\mathrm{~min}^{-1}\right]$ & $\mathrm{q}_{\mathrm{e}, \mathrm{cal}}[\mathrm{mg} / \mathrm{g}]$ & $\mathrm{R}^{2}$ & $\mathrm{k}_{2}[\mathrm{~g} / \mathrm{mg} \cdot \mathrm{min}]$ & $\mathrm{q}_{\mathrm{e}, \mathrm{cal}}[\mathrm{mg} / \mathrm{g}]$ \\
\hline Crab shell & 0.0263 & 0.813 & 0.978 & 0.591 & 2.08 \\
\hline Chitosan & 0.0424 & 0.579 & 0.951 & 0.236 & 0.995 \\
\hline
\end{tabular}


Table 2. Parameters of the Weber-Morris intraparticle diffusion model for adsorption of $\mathrm{Ga}(\mathrm{II})$ on crab shell powder and chitosan

\begin{tabular}{|c|c|c|c|c|c|c|c|c|c|c|c|}
\hline Biosorbent & $\mathrm{k}_{1}$ & $\mathrm{k}_{2}$ & $\mathrm{k}_{3}$ & $\mathrm{C}_{1}$ & $\mathrm{C}_{2}$ & $\mathrm{C}_{3}$ & $\mathrm{R}_{1}{ }^{2}$ & $\mathrm{R}_{2}{ }^{2}$ & $\mathrm{R}_{3}{ }^{2}$ & $k_{p}$ & $\mathrm{R}_{\mathrm{p}}{ }^{2}$ \\
\hline & & $\mathrm{ng} / \mathrm{g} \cdot \mathrm{m}$ & & & & & & & & & \\
\hline Crab shell & 1.31 & 0.077 & 0.053 & - & 1.21 & 1.46 & 1 & 0.948 & 0.996 & 0.0263 & 0.978 \\
\hline Chitosan & 1.73 & 0.111 & 0.005 & - & 1.65 & 2.31 & 1 & 0.904 & 0.887 & 0.0433 & 0.804 \\
\hline
\end{tabular}

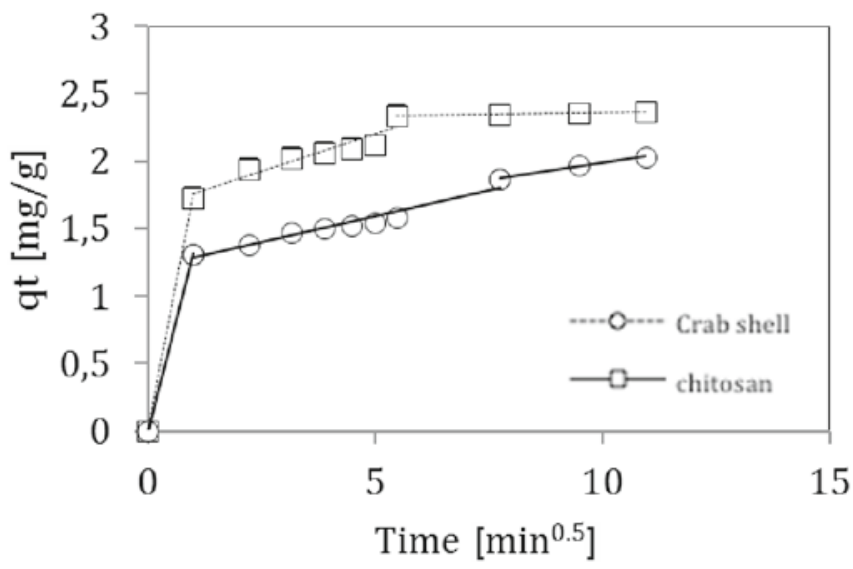

(a)

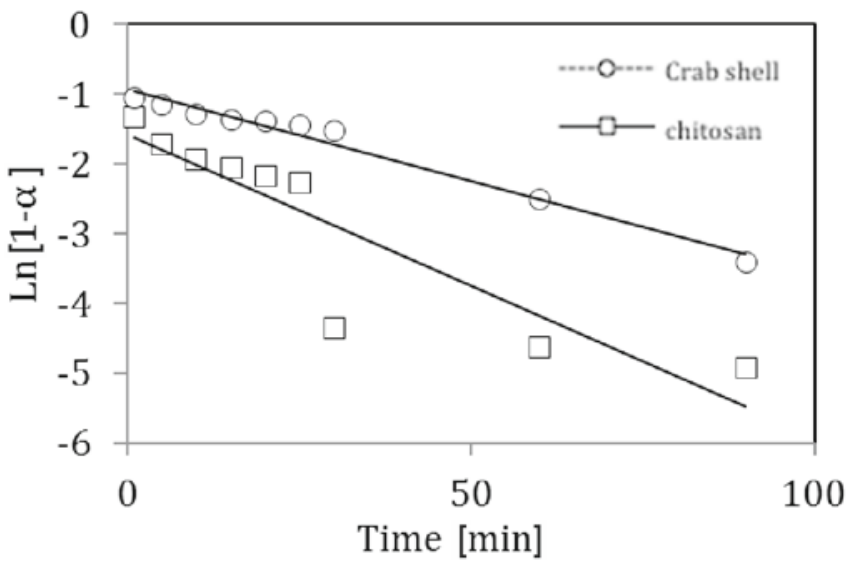

(b)

Figure 6. Weber-Morris plots (a) and particle diffusion controlled-process plot (b) for adsorption of Ga(III) on crab shell and chitosan powder. Conditions: $\mathrm{Ga}(\mathrm{III})$ ion concentration $10 \mathrm{mg} / \mathrm{L}, 100 \mathrm{mg}$ biosorbent, $\mathrm{pH}$ 2.4, agitatation speed of $60 \mathrm{rpm}$ at $25^{\circ} \mathrm{C}$

The $k_{p}$ values observed from Table 2 were not higher than the $k_{1}, k_{2}$ or $k_{3}$ values. Thus by the comparison of the Weber-Morris and intra-particulate diffusivity plot it may be speculated that intra-particle diffusion is not the only factor determining the rate of adsorption of $\mathrm{Ga}$ (III) onto the crab shell and chitosan particles under these operating conditions.

\section{The effect of $\mathrm{pH}$ on $\mathbf{G a}$ (III) biosorption}

In adsorption processes the $\mathrm{pH}$ of the metal ion solution is a very important factor that influences the ionic state of the metal ion(s) present. To this effect, this study investigated the influence of $\mathrm{pH}$ on the biosorption of $\mathrm{Ga}(\mathrm{III})$ onto crab shell and chitosan powders. The effect of $\mathrm{pH}$ can strongly influence the binding sites on the adsorbent, dissociation state and the solution chemistry. The solution chemistry can influence the coordination of $\mathrm{Ga}(\mathrm{III})$ through processes such as hydrolysis, complexation and redox potentials ${ }^{29}$. The effect of $\mathrm{pH}$ on percent adsorption of $\mathrm{Ga}(\mathrm{III})$ ion at different $\mathrm{pH}$ values were presented in Figure 7. From Figure 7, it was observed that the adsorption of $\mathrm{Ga}(\mathrm{III})$ ion onto crab shell powder was increased from $\mathrm{pH} 1$ to 2 , thereafter a small decrease was observed at $\mathrm{pH}$ 2.4. A similar trend was observed for chitosan, however, due to its dissolution properties at lower $\mathrm{pH}$ values the adsorption was not recorded at $\mathrm{pH}$ 1. The maximum percent adsorptions for crab shell and chitosan powder were observed at $\mathrm{pH}$ values 2.0 and 2.4 respectively. There was a steady decrease in $\mathrm{Ga}$ (III) adsorption on chitosan noticed from $\mathrm{pH} 2.4$ to 5. This was due to the decrease in the hydrophilic nature of chitosan and thus its decrease in swelling ability. In pure aqueous $\mathrm{Ga}$ solutions as the $\mathrm{pH}$ value increases from 2.56 to 3.20 the $\mathrm{Ga}$ species changes from $\mathrm{Ga}^{3+} /$ $\mathrm{GaOH}^{2+}$ to $\mathrm{GaOH}^{2+} / \mathrm{GaO}^{+}$, thus for chitosan it was speculated that as the $\mathrm{pH}$ increased the competition for the formation of $\mathrm{GaO}^{+}$was favored over the formation of the ligand-metal coordination comple ${ }^{30}$. As the $\mathrm{pH}$ increases, the presence of these cations in solution was speculated to aid in the $\mathrm{Ga}(\mathrm{III})$ uptake as they probably associated with the free hydroxyl ions.

\section{Effect of initial Ga (III) ion concentration and adsorp- tion isotherms}

The effect of initial Ga(III) ion concentration was studied by varying the ion concentration from $10-100 \mathrm{mg} / \mathrm{L}$ while keeping the other parameters such as agitation time, solution $\mathrm{pH}$, temperature and biosorbent dosage constant. As the metal ion concentration increased the adsorptive capacity of the crab shell and chitosan powders increases. The amino and hydroxyl groups of chitosan form dative bonds with the metal ions in aqueous solutions. To elucidate the probable adsorption mechanism for this increase in adsorption behavior, adsorption isotherm models were used to interrogate the equilibrium data.

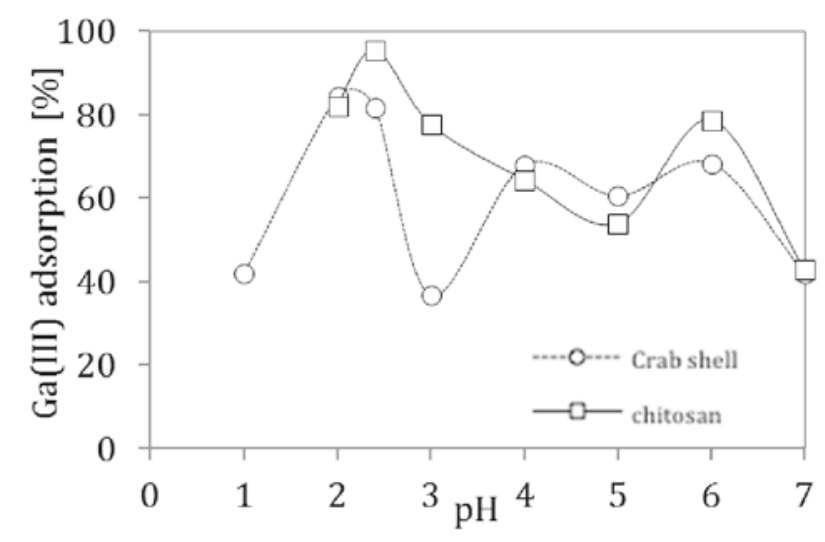

Figure 7. Effect of $\mathrm{pH}$ on biosorption of $\mathrm{Ga}(\mathrm{III})$ onto crab shell and chitosan powder 
The equilibrium data at different initial metal ion concentrations were modeled using Langmuir, Freundlich and the Langmuir-Freundlich adsorption isotherms. From these isotherms it was then possible to relate the concentration of $\mathrm{Ga}$ (III) ion in solution and the adsorbed amount of $\mathrm{Ga}$ (III) at the surface of the adsorbate. The Langmuir isotherm incorporated the maximum adsorption capacity that occurred at a saturated monolayer of $\mathrm{Ga}$ (III) on the surface of the biosorbents. The basis of the Langmuir adsorption isotherm also considers the energy of adsorption and thus can be represented by the following equation:

$q_{e}=\frac{q_{\max } \cdot K_{L} C_{e}}{\left(1+K_{L} C_{e}\right)}$

where $q_{e}$ was the amount of $\mathrm{Ga}(\mathrm{III})$ adsorbed per unit weight of biosorbent $(\mathrm{mg} / \mathrm{g}), q_{\max }$ was the Langmuir theoretical maximum adsorption capacity of the biosorbents and $K_{L}$ was the adsorption energy coefficient. The linear plots for the Langmuir isotherm was shown in Figure $8 \mathrm{a}$ and their correlation coefficients were shown in Table 3. The theoretical maximum monolayer adsorption capacities of $\mathrm{Ga}(\mathrm{III})$ onto the crab shell and chitosan powders were 16.96 and $10.59 \mathrm{mg} / \mathrm{g}$ with adsorption energy coefficients of 9.96 and 11.67 respectively. Both biosorbents had a reasonable correlation to the Langmuir plot, which predicted the existence of a fixed capacity of adsorption sites with equal morphologies on the biosorbent surface. In addition, it was assumed that these adsorption sites had the same energy profiles during adsorption. To further speculate the sorption behavior of $\mathrm{Ga}(\mathrm{III})$ ions onto the biosorbents, the Freundlich isotherm model was used.

The Freundlich isotherm proposes an exponential disparity of the energies at the adsorption sites, and was based on the distribution of the solute between the solid and aqueous phase at equilibrium. Thus assuming that the rate-limiting step is not confined to surface adsorption but multilayer adsorption ${ }^{31}$. This relation was shown below in the Freundlich isotherm equation: $q_{e}=K_{F} C e^{1 / n}$

where $K_{F}$ is the measure of the adsorption capacity and $1 / n$ is the adsorption magnitude. The equilibrium data was expressed in the Freundlich isotherm linear plot and was shown in Figure 8b, and the corresponding parameters were shown in Table 3 . The values of $K_{F}$ were 0.653 and 1.133 for crab shell and chitosan powders respectively. These values, which were a measure of the adsorption capacity, indicated the strength of the adsorptive relation, thus deducing that there was a stronger association of the $\mathrm{Ga}(\mathrm{III})$ ions to the chitosan than the crab shell powder ${ }^{32}$.
Due to the reasonable correlation of the experimental data to the Langmuir and Freundlich adsorption isotherms, the Langmuir-Freundlich isotherm was used to further understand the adsorptive behavior of $\mathrm{Ga}(\mathrm{III})$ onto crab shell and chitosan powders.

The Langmuir-Freundlich isotherm is a combination of the Langmuir and Freundlich adsorption isotherms, however, the advantage of the Langmuir-Freundlich adsorption isotherm is the flexibility of applying both the Langmuir and Freundlich sorption effects to describe the adsorption behavior of $\mathrm{Ga}$ (III) onto the biosorbents. The Langmuir-Freundlich isotherm can be mathematically expressed as the following weighed integrals and can be linearized to the following linear equation ${ }^{\mathbf{3 3}, \mathbf{3 4}}$ :

$q=\int_{-\infty}^{+\infty} g\left(K_{a}\right) \frac{K_{a} C_{e q}}{1+K_{a} C_{e q}} d K_{a}$

$\frac{1}{q_{e}}=\frac{1}{C_{e}^{1 / n}}\left(\frac{1}{K_{L F} q_{m}}\right)+\frac{1}{q_{m}}$

where $\mathrm{g}\left(\mathrm{K}_{\mathrm{a}}\right)$ was the density function, with affinity constant $K_{a}, K_{L F}$ was the Langmuir-Fruendlich constant and $n$ was the heterogeneity parameter. The Langmuir-Freundlich isotherm can be reduced under certain conditions to represent both the Langmuir and Freundlich isotherms with some minor substitutions, as represented in Figures 8c-e. When $n=1$, the Langmuir-Freundlich equation reduces to the Langmuir equation, and when $C_{e q}$ and $K_{a}$ values approach 0 , the Langmuir-Freundlich reduces to the Freundlich equation ${ }^{35-37}$. From Table 3, it was observed that overall, the Langmuir-Freundlich isotherm model for $n=2$ had the highest correlation coefficients for both biosorbents and thus the biosorption of $\mathrm{Ga}$ (III) under these conditions can be more accurately predicted by the consideration of both the Langmuir and Freundlich behaviors. The values of $n=2$ indicated the presence of a heterogeneous system of binding sites for the biosorbents which were capable of adsorbing Ga(III) from aqueous solution.

\section{CONCLUSIONS}

The biosorbent chitosan powder was synthesized through a series of several chemical processes such as deproteination, demineralization, decoloration and deacetylation. The performance of the chitosan powder in $\mathrm{Ga}$ (III) uptake from aqueous solution as compared with the crab shell powder. Batch adsorption experiments were carried out in order to optimize the experimental conditions. The Langmuir, Freundlich and Langmuir-Freundlich adsorption isotherms were used to analyze the adsorption data and obtain the isotherm constants. The

Table 3. Langmuir, Freundlich and Langmuir-Freundlich isotherm model parameters for Ga(III) adsorption on crab shell powder and chitosan

\begin{tabular}{|c|c|c|c|c|c|}
\hline Isotherm Model & Biosorbent & $\mathrm{q}_{\max , \text { cal }}\left[\mathrm{mmg}^{-1}\right]$ & $\mathrm{K}_{\mathrm{LF}}\left[\mathrm{gmg}^{-1}\right]$ & $\mathrm{R}^{2}$ & $\mathrm{n}$ \\
\hline \multirow{2}{*}{ Langmuir } & Crab shell & 16.95 & 9.96 & 0.975 & \multirow{2}{*}{1.0} \\
\hline & Chitosan & 10.59 & 11.69 & 0.949 & \\
\hline Freundlich & Crab shell & - & 0.653 & 0.981 & 1.27 \\
\hline \multirow{6}{*}{ Langmuir-Freundlich } & Crab shell & 7.77 & 1.672 & 0.909 & \multirow{2}{*}{0.5} \\
\hline & Chitosan & 7.36 & 4.292 & 0.878 & \\
\hline & Crab shell & 34.36 & 25.71 & 0.993 & \multirow{2}{*}{1.5} \\
\hline & Chitosan & 27.93 & 34.84 & 0.980 & \\
\hline & Crab shell & 8.15 & 6.470 & 0.995 & \multirow{2}{*}{2.0} \\
\hline & Chitosan & 34.48 & 43.29 & 0.992 & \\
\hline
\end{tabular}




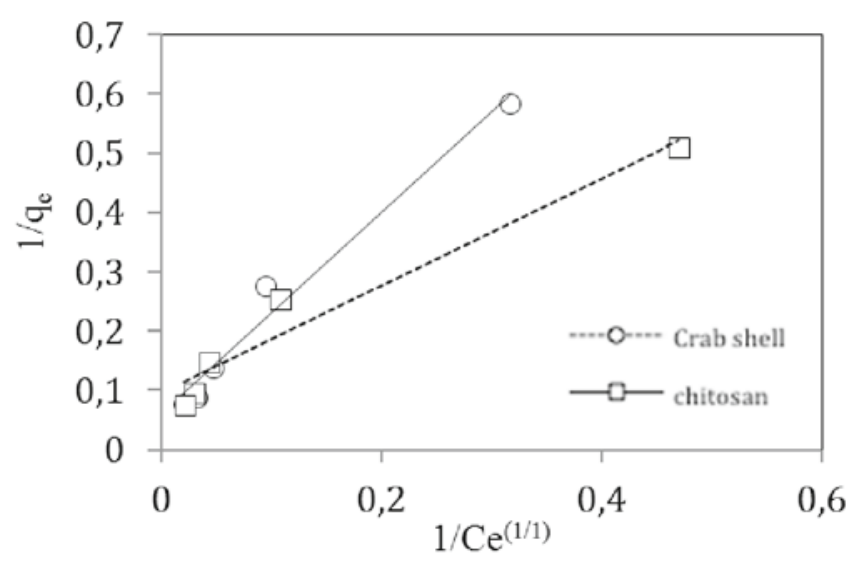

(a)

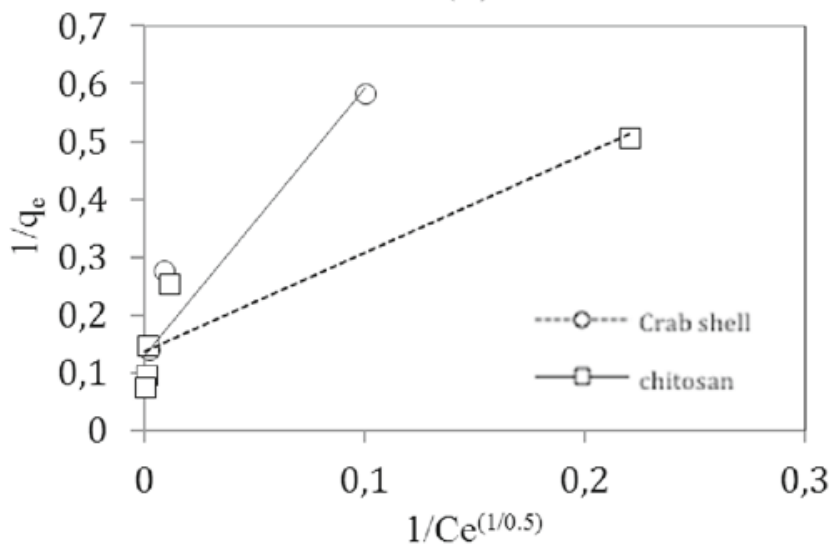

(c)

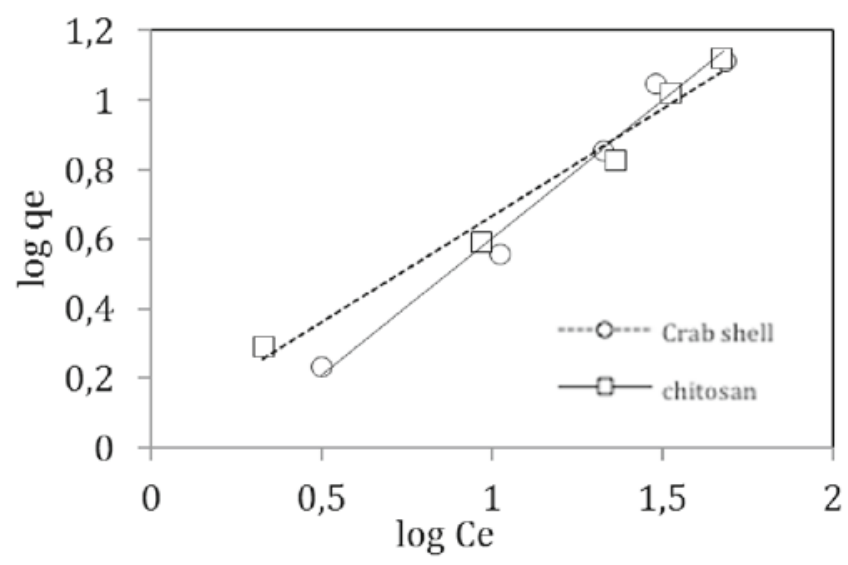

(b)

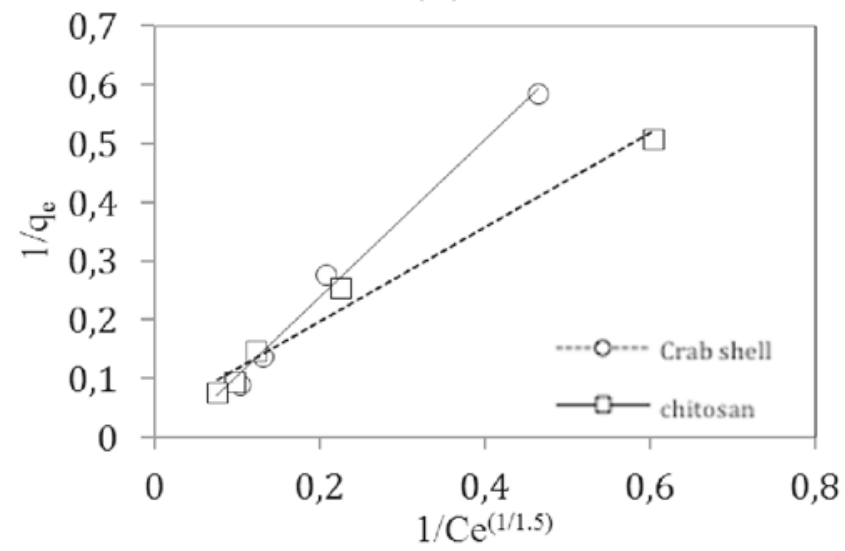

(d)

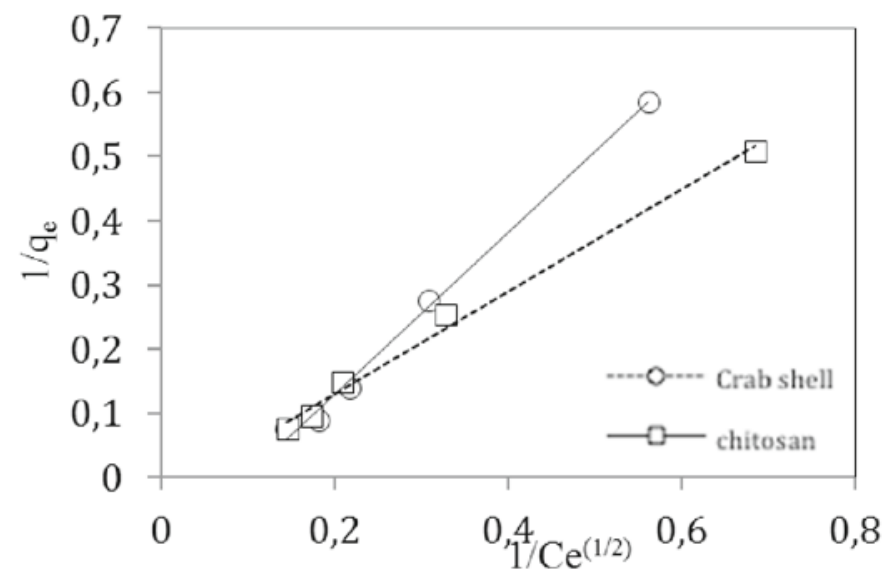

(e)

Figure 8. Langmuir $\mathrm{n}=1.0$ (a), Freundlich (b) and Langmuir-Freundlich isotherm plots for Ga(III) adsorption on crab shell and chitosan powder. $\mathrm{n}=0.5(\mathrm{c}), \mathrm{n}=1.5(\mathrm{~d})$ and $\mathrm{n}=2.0(\mathrm{e})$

relative adsorption capacities were deduced and deemed that crab shell powder and chitosan powder could be used as effective adsorbents for the adsorption and removal of Ga from aqueous sources. The pseudo-second order kinetic model was determined to be the more favorable model based on the correlation coefficient that indicated the reaction between adsorbents and the $\mathrm{Ga}$ (III) ion was monolayer interaction. The maximum monolayer capacities of the crab shell and chitosan powders were found to be 16.95 and $10.59 \mathrm{mg} \mathrm{g}^{-1}$ respectively. Characterization studies indicated amino and hydroxy groups were present and possibly participated in metal uptake; also, the powders exhibit crystalline nature.

\section{LTERATURE CITED}

1. Moskalyk, R.R. (2003). Gallium: the backbone of the electronics industry. Min. Eng. 16 921-929. DOI: http://dx.doi. org/10.1016/j.mineng.2003.08.003

2. Bina, G., Niti, M., Zareena, B.I. \& Indu, S. (2007). Extraction and recovery of $\mathrm{Ga}(\mathrm{III})$ from waste material using Cyanex 923. Hydrometallurgy 87, 18-26. DOI: 10.1016/j.hydromet.2007.01.001. 
3. Wu, C.C. \& Liu, H.M. (2009). Determination of gallium in human urine by supercritical carbon dioxide extraction and graphite furnace atomic absorption spectrometry. J. Hazard. Mat. 163, 1239-1245. DOI: 10.1016/j.jhazmat.2008.07.093.

4. Wu, X., Wu, S., Qin, W., Ma, X., Niu, Y., Lai, S., Yang, C., Jiao, F. \& Ren, L. (2012). Reductive leaching of gallium from zinc residue. Hydrometallurgy 113-114, 195-199. DOI:10.1016/j. hydromet.2011.11. 016.

5. Yu, H.S. \& Liao, W.T. (2011). Gallium: Environmental pollution and Health Effects. In J. Nriagu (Ed.), Reference Module in Earth Systems and Environmental Sciences, Encyclopedia of Environmental Health ( pp. 829-833). London, Elsevier.

6. Chowdhury, S., Swenson, B.L,, Wong, M.H. \& Mishra, U.K. (2013). Current status and scope of gallium nitride-based vertical transistors for high-power electronics application. Semicond. Sci. Technol. 28, 1-8. DOI: 10.1088/0268-1242/28/7/074014.

7. Kramer, D.A. (2003). Gallium. In G.A. Norton \& C.G. Groat (Eds.), Mineral Commodity Summaries (pp. 66-67). Reston, VA. U.S. Government Printing Office.

8. Jaskula, B.W. (2014). Mineral commodity summaries 2012: U.S. Geological Survey. Washington, USA: U.S. Government Printing Office.

9. Gutierrez, B.P.C., Pazos, C. \& Coca, J. (2002). Solvent extraction equilibrium of gallium from hydrochloric acid solutions by amberlite LA-2. J. Chem. Technol. Biotechnol. 61, 241-245. DOI: $10.1002 /$ jctb.280610310.

10. Mujeriego, R. \& Asano, T. (1999). The role of advanced treatment in wastewater reclamation and reuse. Water Sci. Technol. 40(4-5), 1-9. DOI: 10.1016/S0273-1223(99)00479-5.

11. Mahamuni, S.V., Wadgaonkar, P.P. \& Anuse, M.A. (2010). Liquid-liquid extraction and recovery of gallium(III) from acid media with 2-octylaminopyridine in chloroform: Analysis of bauxite ore. J. Serbian Chem. Soc. 75(8), 1099-1113. DOI: 10.2298/JSC090630072M.

12. Huang, C.J., Yang, B.M., Chen, K.S., Chang, C.C. \& Kao, C.M. (2011) Application of membrane technology on semiconductor wastewater reclamation: A pilot-scale study. Desal. 278(1-3), 203-210. DOI: 10.1016/j.desal.2011.05.032.

13. Srinivasa Rao, P., Kalyani, S., Suresh Reddy, K.V.N. \& Krishnaiah, A. (2005). Comparison of biosorption of Nickel(II) and Copper(II) ions from aqueous solutions by Sphaeroplea algae and acid treated Sphaeroplea algae. Sep. Sci. Technol. 40, 3149-3156. DOI: 10.1080/ 01496390500385350.

14. Volesky, B. (1994). Advances in biosorption of metals: Selection of biomass types FEMS. Microbiol. Rev. 14, 291-302. DOI: 10.1111/j.1574-6976.1994.tb00102.x.

15. Xiao, D.Z., Bin, L., Bo, Zhu, Kuang, R., Kuang, X., Xu, B. \& Ma, M. (2010). Crayfish Carapace Micro-powder (CCM): A Novel and Efficient Adsorbent for Heavy Metal Ion Removal from Wastewater. Water 2, 257-272. DOI: 10.3390/w2020257.

16. Varma, A.J., Deshpande, S.V. \& Kennedy, J.F. (2004). Metal complexation by chitosan and its derivatives: A review. Carborhydr. Polym. 55, 77-93. DOI: 10.1016/j.carbpol.2003.08.005.

17. Song, Q.P., Wang, C., Zhang, Z. \& Gao, J. (2014). Adsorption of $\mathrm{Cu}(\mathrm{II})$ and $\mathrm{Ni}(\mathrm{II})$ using a Novel Xanthated Carboxymethyl Chitosan. Sep. Sci. Technol. 49(8), 1235-1243. DOI: 10.1080/01496395.2013. 872656.

18. He, Z., Branford-White, C., Zhou, Y., Nie, H. \& Zhu, L. (2010). Papain Adsorption on Chitosan-Coated Nylon-Based Immobilized Metal Ion $\left(\mathrm{Cu}^{2+}, \mathrm{Ni}^{2+}, \mathrm{Zn}^{2+}, \mathrm{Co}^{2+}\right)$ Affinity Membranes. Sep. Sci. Technol. 45(4), 525-534. DOI: 10.1080/01496390903484784.

19. Kalyani, S., Ajithapriya, J., Srinivasa Rao, P. \& Krishnaiah, A. (2005). Removal of copper and nickel from aqueous solutions using chitosan coated on perlite as biosorbent. Sep. Sci. Technol. 40, 1483-1495. DOI: 10.1080/01496390801940762.

20. Liu, C.X. \& Bai, R.B. (2006). Adsorptive removal of copper ions with highly porous chitosan/cellulose acetate blend hollow fiber membranes. J. Memb. Sci. 284, 313-322. DOI: 10.1016/j.memsci.2006.07.045.
21. Cadogan, E.I, Lee, C.H., Popuri, S.R. \& Lin, H.Y. (2014). Effect of Solvent on Physico-Chemical Properties and Antibacterial Activity of Chitosan Membranes. Int. J. Polym. Mater. 63(14), 708-715. DOI: 10.1080/00914037.2013.867264.

22. Song, Q., Wang, C., Zhang. Z. \& Gao, J. (2014). Adsorption of $\mathrm{Cu}(\mathrm{II})$ and $\mathrm{Ni}(\mathrm{II})$ using a Novel Xanthated Carboxymethyl Chitosan. Sep. Sci. Technol. 49(8), 1235-1243. DOI: 10.1080/01496395.2013.872656.

23. Cadogan, E.I, Lee, C.H., Popuri, S.R. \& Lin, H.Y. (2014). Efficiencies of chitosan nanoparticles and crab shell particles in europium uptake from aqueous solutions through biosorption: Synthesis and Characterization. Int. Biodeterior. Biodegrad. 95(A), 232-240. DOI: http://dx.doi.org/10.1016/j. ibiod.2014.06.003

24. Ji, Y., Gao, H., Sun, J. \& Fang, C. (2011). Experimental probation on the binding kinetics and thermodynamics of $\mathrm{Au}-$ (III) onto Bacillus subtilis. Chem. Eng. J. 172, 122-128. DOI: 10.1016/j.cej.2011.05.077.

25. Ho, Y.S. \& McKay, G. (2000). The kinetics of sorption of divalent metal ions onto sphagnum moss peat. Water Res. 34(3), 735-742. DOI: 10.1016/S0043-1354(99)00232-8.

26. Vijaya, Y., Popuri, S.R., Boddu, V.M. \& Krishnaiah, A. (2008). Modified chitosan and calcium alginate biopolymer sorbents for the removal of nickel (II) through adsorption, Carbohydr. Polym. 72, 261-271. DOI: 10.1016/j.carbpol.2007.08.010.

27. Ho, Y.S. \& McKay, G. (1998). Kinetic models for the sorption of dye from aqueous solution by wood. Trans. Inst. Chem. Eng. Part B. 76,183-188. DOI: 10.1205/095758298529326.

28. Uğurlu, M. (2009). Adsorption of a textile dye onto activated sepiolite. Micropor. Mesopor. Mater. 119, 276-283. DOI: 10.1016/j.micromeso.2008.10.024.

29. Vanleugenhaghe, C., De Zoubov, N. \& Pourbaix, M. (1974). Gallium. In M. Pourbaix (Ed.), Atlas of Electrochemical Equilibria in Aqueous Solutions (pp. 428-435). Texas, USA: Pergamon Press Ltd.

30. Ng, C., Losso, J.N., Marshall, W.E. \& Rao, R.M. (2002). Freundlich adsorption isotherms of agricultural by-product-based powdered activated carbons in a geosmin-water system. Bioresour. Technol. 85(2), 131-135. DOI: 10.1016/S09608524(02)00093-7.

31. Tang, X.W., Wang, Y. \& Li, Z.Z. (2009). Removal of Heavy Metal from Aqueous Solution using Chinese Loess Soil. In Advances in Environmental Geotechnics: International Geoenvironmental Engineering Symposium, 8-10 September 2009 (pp. 313-319). Hangzhou China: Springer Berlin Heidelberg.

32. Limousin, G., Gaudet, J.P., Charlet, L., Szenknect, S., Barthes, V. \& Krimissa, M. (2007). Sorption isotherms: A review on physical bases, modeling and measurement. Appl. Geochem. 22, 249-275. DOI: 10.1016/j.apgeochem.2006.09.010.

33. Clement, T.P., Sun, Y., Hooker, B.S. \& Petersen, J.N. (1998). Modeling Multispecies Reactive Transport in Groundwater Aquifers. Ground Water Monit. R. 18(2), 79-92.

34. Jeppu, G. \& Clement, T.P. (2012). A modified LangmuirFreundlich isotherm model for simulating $\mathrm{pH}$-dependent adsorption effects. J. Contam. Hydrol. 129-130, 46-53. DOI: 10.1016/j.jconhyd.2011.12. 001.

35. Turiel, E., Perez-Conde, C. \& Martin-Esteban, A. (2003). Assessment of the crossreactivity and binding sites characterization of a propazine-imprinted polymer using the Langmuir-Freundlich isotherm. Analyst. 128(2), 137-141. DOI: 10.1039/B210712K.

36. Umpleby, R.J., Baxter, S.C., Chen, Y., Shah, R.N. \& Shimizu, K.D. (2001). Characterization of Molecularly Imprinted Polymers with the Langmuir- Freundlich Isotherm. Analyt. Chem. 73(19), 4584-4591. DOI: 10.1021/ ac0105686.

37. Mohaylov, I. \& Distin, P.A. (1995). Gallium solvent extraction from acidic solutions with octyl phenyl acid phosphate (OPAP) reagents. Hydrometallurgy 37, 221-234. DOI: 10.1016/0304-386X(94)00045-5. 